\title{
A New World for Chemical Synthesis?
}

\author{
Steven V. Ley, Yiding Chen§, Daniel E. Fitzpatrick§, and Oliver May§
}

\begin{abstract}
This perspective seeks to provide an overarching vision of the current state of chemical synthesis methodology using machinery as enabling tools. It highlights current capabilities and limitations in this highly digitallyconnected world and suggests areas where new opportunities may arise in the future by going well beyond our present levels of innovation and automation. There is a new need for improved downstream processing tools, advanced reactor design, computational predictive algorithms and integration of robotic systems to maximise the human resource to facilitate a new era in the assembly of our functional materials.
\end{abstract}

Keywords: 3D Printing · Camera vision · Continuous processing · Flow chemistry · Machine learning Reaction telescoping $\cdot$ Self optimisation $\cdot$ Wearable devices

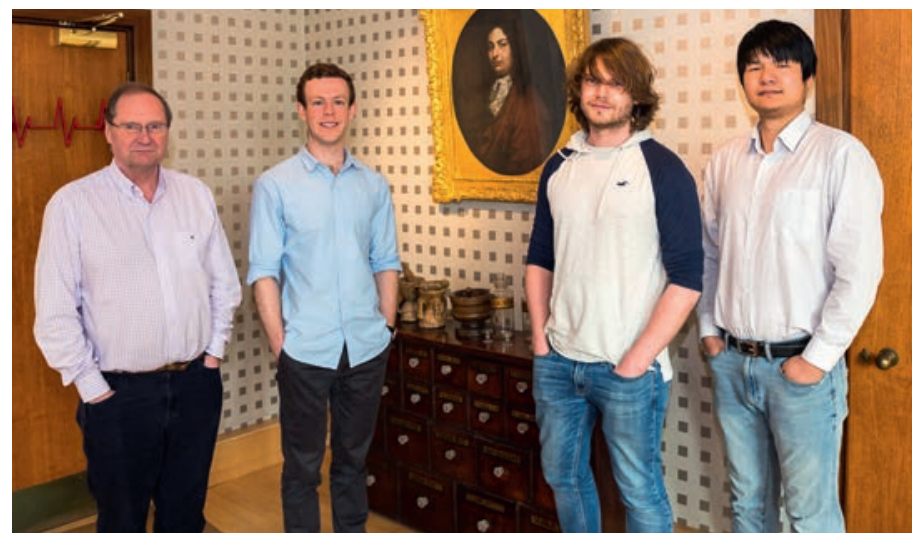

Professor Steven Ley is currently Professor of Chemistry at the University of Cambridge. Steve obtained his $\mathrm{PhD}$ from Loughborough University. He was appointed as a lecturer at Imperial College in 1975, promoted to Professor in 1983, and then to Head of Department in 1989. In 1990 he was elected to the Royal Society (London) and was President of The Royal Society of Chemistry from 2000 to 2002. Steve's research interests are varied and span many disciplines including new synthetic methodologies, the total synthesis of natural products and the development of enabling technologies for chemical synthesis - especially in the area of flow chemistry technologies. He has published over 880 papers and has been honoured with 50 major awards, the most recent being the 2018 Arthur C. Cope Award of the American Chemical Society.

Dr. Yiding Chen received his undergraduate degrees in 2013 from the [2+2] programme between Fudan University, China and University of Birmingham, UK. He then did his D. Phil studies with Prof. Michael Willis at University of Oxford. From 2018 he is working for Prof. Ley as a research associate, with focus on development of photoredox synthetic methodology in both batch and flow.

Daniel Fitzpatrick is currently a Post-Doctoral Research Associate at the University of Cambridge, having graduated in 2017 with a PhD under the supervision of Prof. Steven V. Ley. Prior to Cambridge, he graduated with a Bachelor of Engineering

${ }^{*}$ Correspondence: Prof. Steven V. Ley, E-mail: svl1000@cam.ac.uk Department of Chemistry, University of Cambridge, Lensfield Road, Cambridge CB2 1EW, UK

$\S$ The authors contributed equally
(Hons) with First Class Honours from The University of Auckland in May 2013, specialising in Chemical and Materials Engineering. His current research focusses on bridging Chemistry with Chemical Engineering, with a particular focus on the integration of advanced computer control systems during the synthetic preparation of APIs.

Oliver May received his undergraduate degree from Loughborough University in 2011. Following a summer placement at the University of Oxford he joined the Defence Science and Technology Laboratory (Dstl) as a graduate chemist. In 2017 he spent several months on secondment in the ITC and Whiffen Laboratories investigating enabling technologies. Following his secondment he is now completing a sponsored $\mathrm{PhD}$ under the supervision of Prof. Steven Ley and Prof. Matthew Gaunt.

\section{Introduction}

We are often asked about the future of flow chemistry and what's next. Rather than attempt to answer this rather negative question and also dangerously try to predict the future, we take the view that we are only at the beginning of an exciting new era in the assembly of our functional molecules. ${ }^{[1]}$ Being more conscience of our environment and aiming to avoid some of our labour intensive and wasteful practices of the past, we are now poised to take full advantage of our machine-assisted digital world and consider going beyond the 12 Principles of Green Chemistry which have been an important charter for synthesis chemists for over 20 years. Indeed, we have been advocating this machine-assisted enabling technology approach for some years now ${ }^{[2]}$ so as to improve reproducibility and efficiency of synthesis through holistic systems understanding, ${ }^{[3]}$ a consideration increasingly supported by the regulators of our science. ${ }^{[4]}$ There is no doubt that flow chemistry and associated continuous processing methods have delivered on this agenda ${ }^{[5]}$ at least to a point in time whereby we can recognize many tangible benefits that accrue through improved management of exotherms, ${ }^{[6]}$ handling of hazardous materials ${ }^{[7]}$ including reactive gases, ${ }^{\left[{ }^{[8}\right.}$ self-optimizing protocols, ${ }^{[9]}$ together with control of high and low temperatures ${ }^{[10]}$ and pressures, ${ }^{[11]}$ for example. Through the application of bespoke or commercially available equipment considerable modular versatility ${ }^{[12]}$ is available over a wide range of reaction scales and chemistries.

Furthermore, as researchers have acquired the necessary skill-set to operate these technologies successfully, ${ }^{[13]}$ we are seeing wide integration and innovation ${ }^{[1 a]}$ at all levels and even the founding of new journals in the area. However, it is not the purpose of this invited perspective to review "what has been done," as this has been amply covered in numerous other reviews, ${ }^{[5 b, 14]}$ 
but "what needs to be done." Clearly, what follows is a personal selection and is in no way exhaustive. It is meant to encourage new entrants to the field and stimulate debate since in many ways we are talking of disruptive technologies and change in synthesis philosophy often beyond individuals' current comfort zones. For example, trusting their decisions and productivity to robots and machinery across remote sites and time domains ${ }^{[12 a]}$ or using crowd-sourced validation and approvals are often seen as alien to many traditional methods. ${ }^{[15]}$ Nevertheless, we are getting better at collecting and analysing data ${ }^{[16]}$ that goes way beyond the knowledge coming from an individual experiment to encompass broader aspects such as the demand on resources or general societal impact.

The developing use of predictive algorithms, ${ }^{[17]}$ the cloud and increasing availability of open source software ${ }^{[18]}$ massively enhances our capabilities. Indeed, the modern world around us is moving faster than the current conservative praxis of molecule making (with some exceptions). We need to embrace change and live in harmony with our machines. ${ }^{[19]}$

This article examines a variety of selected topics that are evolving rapidly (Fig. 1). Collectively they are shaping how future molecular assembly platforms may function at least at the research laboratory level. Many of the continuous processing methods are already well integrated on scale.

The examples are broadly chosen to reflect where opportunities are arising collectively rather than be viewed as isolated topics.

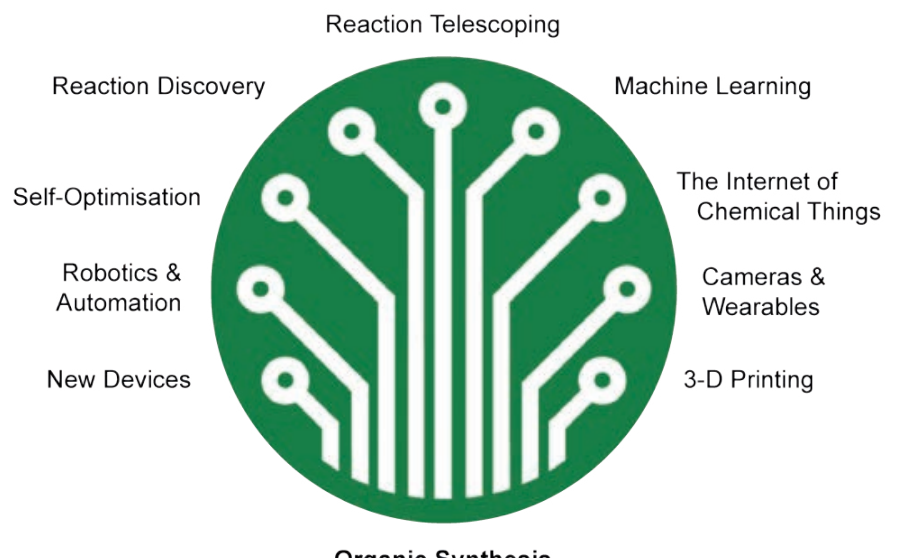

Fig. 1.Developing machine-based technologies for organic synthesis.

\section{Embracing Interdisciplinary Technologies}

\subsection{Head-up Displays, Wearable Devices and Mixed Reality}

A number of recent developments in visualisation technologies, such as the Microsoft Hololens (Fig. 2), Facebook's Oculus Rift and mobile development efforts embedded into iOS and Android devices, have driven innovation in the area of consumer virtual reality (VR) and augmented reality (AR). As is common with new consumer technologies, it is to be expected that interactive and immersive environments will not only be limited to more leisurely pursuits such as video gaming, but also expand into the professional environment in due course.

Indeed, within the scientific arena ${ }^{[20]}$ there have already been efforts to adapt AR for educational purposes with a recent report describing the use of smartphones to aid with classroom teaching. ${ }^{[21]}$ In this example, the relative positions of printed markers were monitored by a smartphone camera to display interactive 3-dimensional (3D) models.

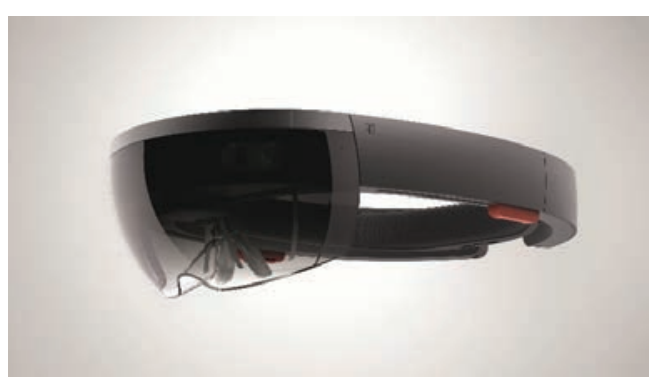

Fig. 2. The Hololens from Microsoft creates new opportunities for mixed reality approaches to synthesis, both planning and execution. Image supplied by Microsoft Press Office.

The same concept had been previously harnessed by our own research group to aid with molecular visualisation, particularly in the realm of mechanism representation. ${ }^{[22]}$ Results from computational studies were translated into 3D models which could be seen in an interactive AR environment generated using QR-code markers (Fig. 3). One can envisage such an approach finding extensive use in research dissemination and published manuscripts, particularly to represent more complex molecular processes. With smartphones and tablets being in near ubiquitous use globally, the barrier of entry is greatly reduced.

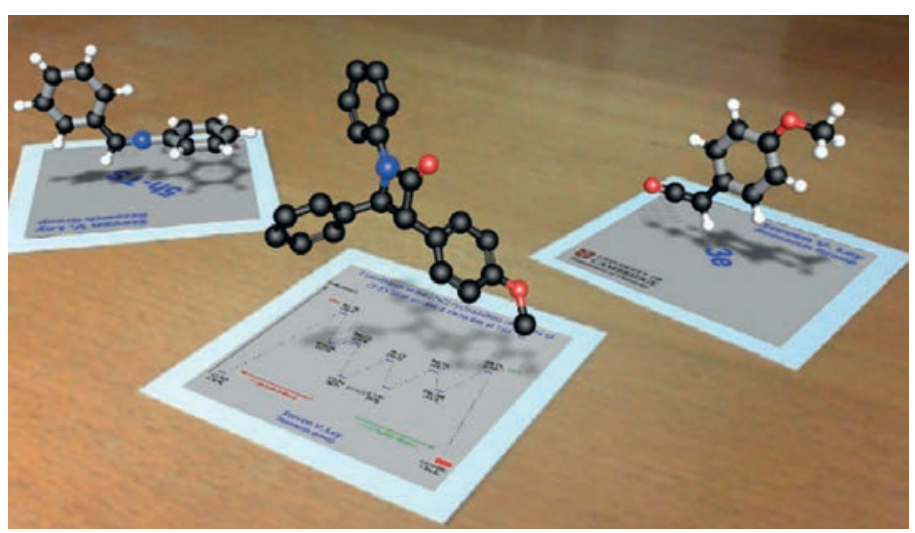

Fig. 3. Paper markers have been used in conjunction with inexpensive consumer web cameras to create interactive environments for the display of complex computational results. ${ }^{[22]}$ Reproduced with permission, (C) Georg Thieme Verlag KG.

This 'mixed reality' approach will have increasing importance in workplace safety, especially in laboratory environments and larger-scale operations in process development and manufacturing. ${ }^{[23]}$ Access to live equipment parameters, material composition streams and atmospheric parameters such as gas compositions will give workers increased insight into their operations. Wearable sensors, ${ }^{[24]}$ potentially even implants, and the application of facial recognition systems in the laboratory can offer further tailoring of information to specific individuals and compliance monitoring, especially when combined with the Internet of Chemical Things. ${ }^{[25]}$ Rapid sharing of graphical information and equipment design will become commonplace.

\subsection{Eyes-on: Cameras as an Enabling Technology and the Open Source Approach}

Although an extensive review on the use of enabling camera technology in flow chemistry programmes has been published previously, ${ }^{[26]}$ we believe its importance cannot be overstated. Cameras are finding increasing use in AR and VR to present information, yet they can also be exploited to aid with direct experimentation. ${ }^{[27]}$ 
One such example is hyperspectral imaging, which grants insight into reactions that cannot be seen by the naked eye. From a safety perspective this enhanced monitoring and oversight can be invaluable - especially for reactions that may be prone to exothermic runaway. Thermal imaging can detect rapid changes in reaction temperatures in real-time, providing feedback that can be harnessed for hazard control.[28]

The rise of importance of precompetitive research has led to extensive development of open source technologies, which facilitates simple propagation of new ideas between research teams. Recent reports have harnessed open-source ideas to aid with multiphasic reaction execution, ${ }^{[29]}$ downstream processing of crude reaction mixtures ${ }^{[30]}$ and combining multiple unit operations together for more advanced applications of reaction automation. ${ }^{[31]}$

We believe that inexpensive computer control devices, such as the Raspberry Pi and Arduino systems, ${ }^{[32]}$ will fuel adoption of these new enabling techniques, further enhancing the open-source community by direct feedback from different sectors. ${ }^{[33]}$

\subsection{Machine Learning, Reaction Discovery, Reaction Optimisation}

Modern developments in computational power have driven advances in machine learning ${ }^{[34]}$ and artificial intelligence algorithms, such as deep learning concepts, ${ }^{[35]}$ a trend which shows no sign of slowing. From a synthesis perspective, this machineassisted approach touches all stages of the pipeline: compound discovery, design of synthesis route, optimisation and even mechanistic analysis; ${ }^{[36]}$ all of which generate valuable data to feed back into the system for future investigations and reinforcements.

There have been extensive reviews published in the area of modern advances in drug discovery and compound design, ${ }^{[37]}$ and thus rather than detailing this here we direct interested readers to some existing literature in the area. ${ }^{[38]}$

Retrosynthesis has been a topic to receive a particular boost from machine learning, ${ }^{[39]}$ with modern applications enabling the ranking of different routes by multiple criteria such as cost, environmental impact and expected reaction performance. ${ }^{[40]}$ One can envisage upcoming generations of electronic laboratory notebooks and the open data sharing policies of research funders will augment the potential of machine-learning approaches still further. Indeed, for computer-driven learning the failed experiment can hold as much importance as those which are successful. The development of standardised chemical data formats and publication strategies will play an important role into the future.

The ease of automation of continuous flow techniques presents promising opportunities for reaction discovery. ${ }^{[41]}$ A recent report described the combination of analytical apparatus (a mass spectrometer, benchtop NMR unit and infrared spectrometer) with reactor systems to seek out unexplored reactivity. ${ }^{[42]} \mathrm{A}$ library of starting materials was supplied to machine-learning algorithms which cycled through different combinations until unexpected analytical hits were observed, thus leading to discovery of novel reactivity. The rise of new and unusual processing techniques, such as acoustic droplet formation, have also led to advanced applications such as an automated reaction exploration platform. ${ }^{[43]}$
Algorithm-powered approaches have already been shown to aid chemists with the selection of suitable conditions for their reactions, ${ }^{[44]}$ cutting the time spent on exploratory reaction trials, reducing the impact of our work and accelerating synthesis. We expect such an influence to continue as useful applications quell scepticism, lest critics be left behind.

There is significant potential for the understanding of reaction conditions $^{[45]}$ and their effects on process outcomes, as brought about by data collection and analysis aided by machine learning approaches, to increasingly accelerate reaction optimisation tasks. ${ }^{[46]}$ Continuous synthesis techniques are particularly amenable to developments in this area owing to increased control over reaction parameters, ease of integration of detectors and rapid reaction times, as highlighted in a number of reviews.[2a,47] Indeed, there have been a number of reports where computer control systems were exploited to approach optimisation problems in the same manner as a chemist would manually. Our own group has been active in this area, with reports detailing efforts where not only yield was optimised but also energy consumption, material consumption and throughput.[9a,12a] Other approaches have followed automated optimisations towards a Pareto front of multiple parameters, ${ }^{[48]}$ applications to polymer synthesis, ${ }^{[49]}$ and versatility in application as driven by apparatus modularity. ${ }^{[50]}$

Optimisation need not be limited solely to reaction conditions, however. Instead, synthesis integration with assay systems (or similar) can offer unique benefits such as automated binding optimisation for target structures. ${ }^{[51]}$ Such 'make-and-screen' ${ }^{[52]}$ operations have the potential to accelerate the drug discovery and development process, bringing new therapeutic compounds to market sooner.

\section{Reactor Design}

\subsection{Photochemistry}

The resurgent interest in photochemistry and the powerful applications to photoredox processes using LED irradiation have, in part, been enabled by the availability of new equipment. This has impacted at scale and in the development of high throughput experimentation techniques for new reaction discovery.

In terms of continuous photochemistry methods, this has been well covered in numerous books, ${ }^{[53]}$ reviews ${ }^{[54]}$ and research articles. ${ }^{[55]}$ Several photo-reactor systems are now commercially available, such as the Vapourtec UV-150, Uniqsis PhotoSyn and Rayonet reactor. More niche challenges employed bespoke equipment, for example to overcome the problem of overirradiation and long reaction times during a photodehydro-Diels-Alder reaction. ${ }^{[56]}$ Rapid prototyping of photochemical reactors via 3D printed devices (Fig. 4) maximises photo-efficiency and better over-all performance. ${ }^{[57]}$

There is also a trend to use higher-intensity and narrowerbandwidth light sources to give maximum throughput and lower catalyst loadings to shorten the reaction time. ${ }^{[58]} \mathrm{A}$ recent example utilised a high-intensity laser in combination with a continuous stirred tank reactor (CSTR) to scale the process to achieve kilogram per day throughput. ${ }^{[59]}$ Innovation, however, to further increase scale is still ongoing.

Applications of photochemical reactions are not restricted to artificial light sources, with a number of reports detailing

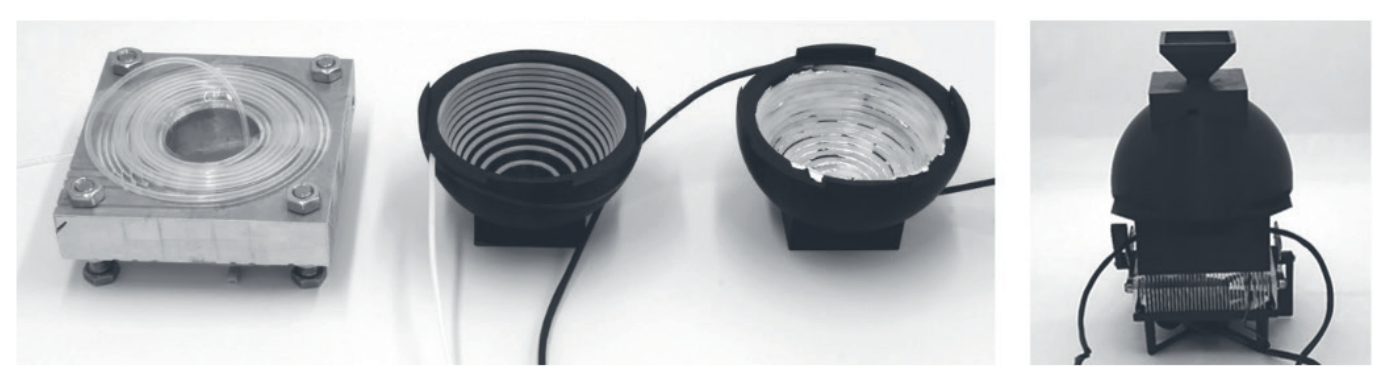

Fig. 4. The use of a specialised 3D-printed photoreactor enhanced photo-efficiency and reaction performance. ${ }^{[57]}$ Reproduced with permission, WILEY-VCH Verlag $\mathrm{GmbH} \&$ Co. KGaA, Weinheim. 
Fig. 5. a) Working principle of the LSC-PM. The dye molecule doped in the photoreactor absorbs solar light, concentrates and re-emits to the microchannel at a suitable wavelength for the reaction; b) Wavelength conversion scheme of the LSC-PM. The fluorescent dye LR305 harvest solar light in a relatively wide spectrum (red) where its emission wavelength (green) overlaps with the absorption range of the photocatalyst MB (blue); c) Photocycloaddition of 9,10-diphenylanthracene with singlet oxygen, catalysed by $M B{ }^{\left[{ }^{[3]}\right]}$ Adapted with permission, WILEY-VCH Verlag GmbH \& Co. KGaA, Weinheim. a

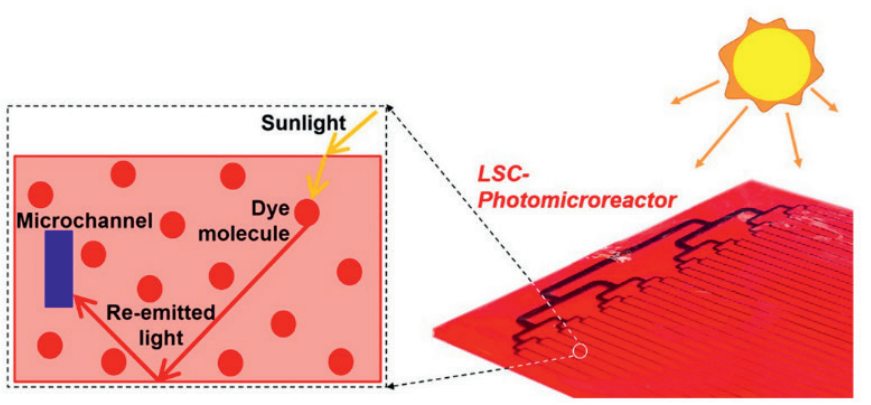

b

C

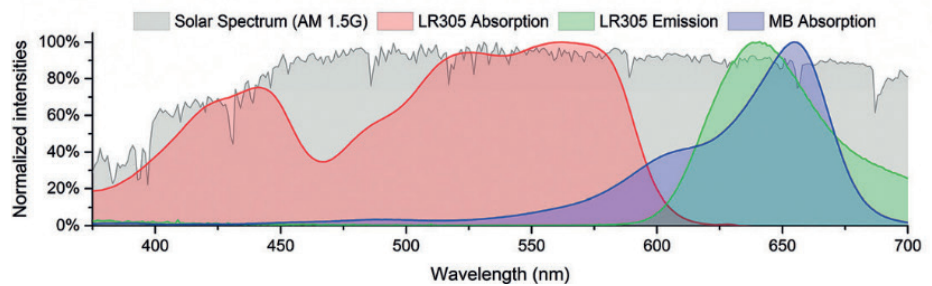

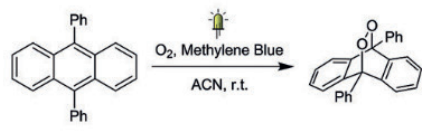

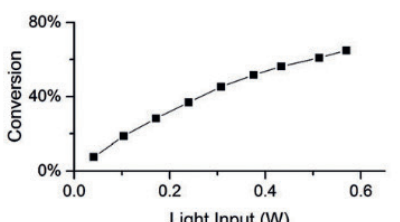

the harnessing of solar light instead. ${ }^{[60]}$ While there is unpredictability with natural light sources which has hindered uptake, ${ }^{[61]}$ the development of new reactors are overcoming some of the issues, ${ }^{[62]}$ but more work in this area is required. One example was the development of a luminescent solar concentrator photomicroreactor (LSC-PM), which concentrates the solar light and focusses the energy to a narrow wavelength region (Fig. 5). ${ }^{63]}$

Recent reports have detailed innovative reagent and catalyst delivery systems as applied to photoredox chemistry. For example, a nebuliser-based delivery system was exploited by Vassilikogiannakis et. al., ${ }^{[64]}$ others have reported the application of the paper spray ionization method for the oxidation of alcohols to carboxylic acids, ${ }^{[65]}$ and a packed-bed photoreactor system containing immobilised Rose Bengal proved useful for photo-oxidation of alkenes using oxygen to avoid downstream processing problems. ${ }^{[66]}$

An enhanced and scalable flow photochemical [2+2] cycloaddition reaction between maleic anhydride and ethylene has been achieved by merging photochemistry with computational methods. Density functional theory (DFT) was applied to calculate the triplet energies of substrates, which were then matched with that of the photosensitizers to provide the optimal conditions. ${ }^{[67]}$

\subsection{Electrochemistry}

Recent developments in electrochemical reactor design ${ }^{[68]}$ are similarly advancing the field of electroorganic synthesis. ${ }^{69]}$ Using new continuous flow electrochemical equipment leads to greater reproducibility and reaction efficiency when compared to standard batch approaches, especially on scaling up. ${ }^{[70]}$

The barrier to entry in the field is changing as new equipment becomes available and biased opinions are moderated by success. New reviews exploring the design of flow electrolysis cells for laboratory-scale synthesis, ${ }^{[71]}$ in terms of modularity and scalability have been published. ${ }^{[72]}$ Some innovative designs include the use of nanowires as three-dimensional porous metal electrodes (Fig. 6), ${ }^{[73]}$ although applications of this device in synthesis have yet to be explored.

\subsection{Biocatalysis}

Known to deliver products with high chemo-, regio- and stereo-selectivity, biocatalysis is finding increasing applications in synthesis. ${ }^{[74]}$

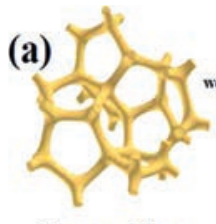

Copper foam

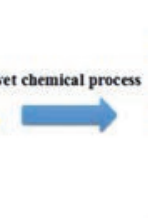

CuO nanowires

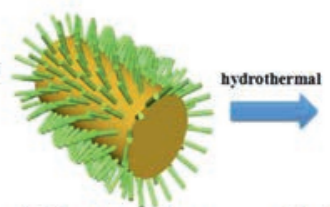

CuO-ZnO nanowires
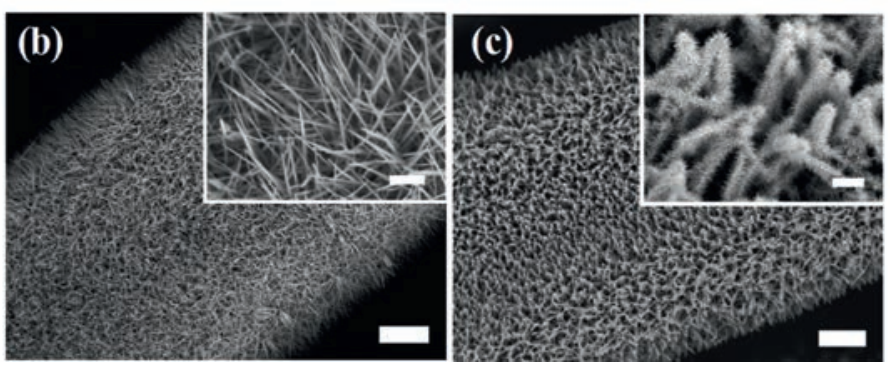

Fig. 6. Example of a porous electrode. a) Synthesis process of the branched $\mathrm{CuO}-\mathrm{ZnO}$ nanostructure. b) SEM image of $\mathrm{CuO}$ nanowires. c) SEM image of branched CuO-ZnO nanowires. (Scale bar for low-magnification: $10 \mu \mathrm{m}$. Scale bar for high-magnification: $2 \mu \mathrm{m})$. Reprinted with permission from ref. [73a]. Copyright 2018 American Chemical Society.

Among the more important developments is the use of immobilised systems since these can aid downstream processing and facilitate product purification. ${ }^{[75]}$ Many enzyme flow reactors have now been commercialised, such as the NanoSprings (Strem) ${ }^{[76]}$ and EziG (EnginZyme AB, Sweden) systems. ${ }^{[77]}$

A particular challenge, however, in flow biocatalysis is their integration into multiple step sequences (Fig. 7). ${ }^{[78]}$ Two comprehensive reviews ${ }^{[79]}$ address some of these issues and we comment further later in this perspective.

\subsection{Gas-Liquid Reactions}

Innovations during the handling of gases in the research environment have also seen significant changes in recent times owing to equipment development.

Introduction of gases into liquid streams using microchip mixers ${ }^{[80]}$ or mass flow controllers ${ }^{[81]}$ can achieve enhanced mixing. Other methods improving inter-phase contact through the use of a nebuliser-based microreactor, ${ }^{[82]}$ a mesh contactor ${ }^{[83]}$ or a falling-film microreactor ${ }^{[84]}$ are available. The application of gas-permeable materials in flow reactor enables easier merging 

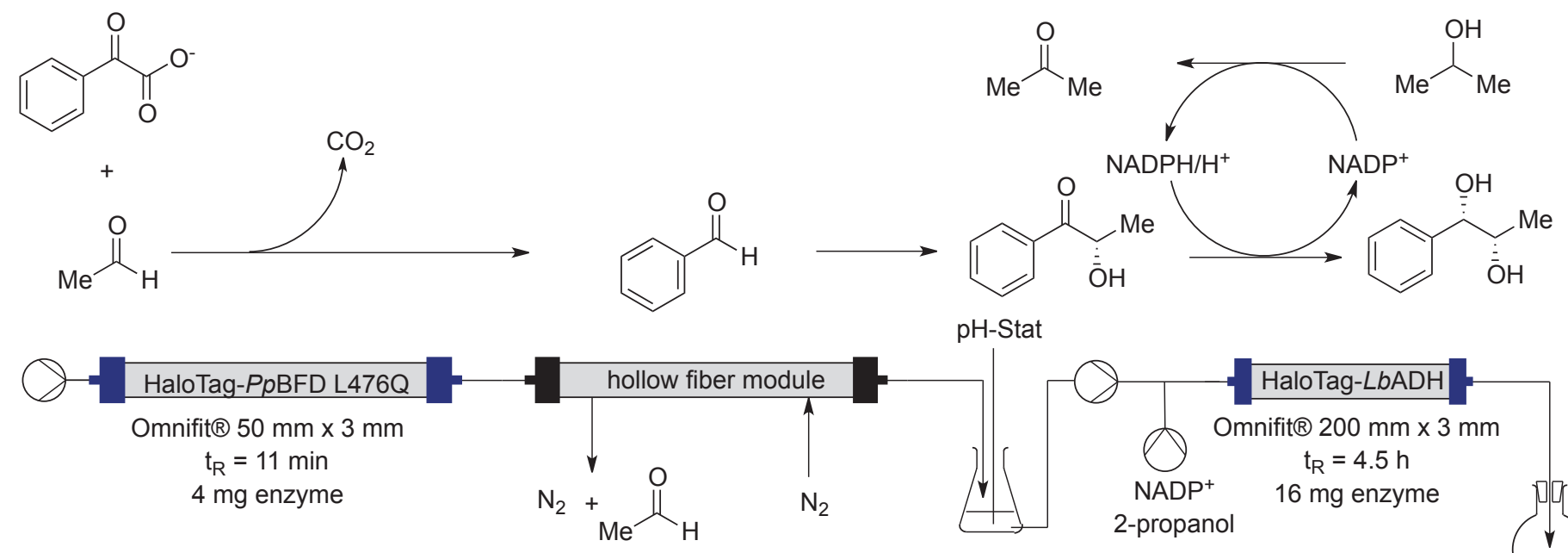

$\mathrm{pH}-\mathrm{Stat}$

Fig. 7. Example of a cascade biocatalytic reaction using enzymes (PpBFD L476Q and LbADH) immobilised with the HaloTag (Promega) system for the two-step synthesis of (1S,2S)-1-phenylpropane-1,2-diol. ${ }^{[78 c]}$

of the two phases ${ }^{[8 b]}$ via the immersion of liquid phase carried with a semipermeable tube in the gas atmosphere. ${ }^{[85]}$ The design of tube-in-tube gas-liquid microreactors ${ }^{[8 \mathrm{a}, 86]}$ allows efficient delivery of many different gases into a flowing liquid stream (Fig. 8).

\subsection{Extreme Conditions}

Operating continuous flow processes can alleviate certain safety issues when operating under extreme conditions, due to smaller working reactor volumes. The benefits are recognised in multiple reviews ${ }^{[1 \mathrm{c}, 87]}$ and book chapters. ${ }^{[88]}$ Recent research articles exploit these opportunities to execute solvent-free $\mathrm{H}_{2}$ reduction, ${ }^{[89]}$ hydrogen-borrowing alcohol amination, ${ }^{[90]}$ thermal Boc deprotection, ${ }^{[10 e, 91]}$ Diels-Alder reactions, ${ }^{[92]} \mathrm{N}$-monomethylation transformations ${ }^{[93]}$ and air oxidation reactions ${ }^{[94]}$ among many others.

While many of these examples were conducted on commercially-available flow platforms, bespoke systems have also been deployed to good effect. For example a high-temperature and high-pressure reactor was utilised during the trifluoromethylation of carbon-rich substrates. ${ }^{[95]}$ Heating by electrical resistance elements ${ }^{[96]}$ (Fig. 9) as well as microwave irradiation has also been used to achieve more extreme reaction conditions. [97]

\subsection{High-temperature Reactions}

The high-pressure and high-temperature conditions generated under pyrolysis make it an alternative to microwave (MW) chemistry. Several reactions previously reported under MW conditions showed improved yield and shortened reaction times. ${ }^{[98]}$

One area which has been deployed for synthesis is Flash Vacuum Pyrolysis (FVP) in which starting materials are distilled through a furnace, exposing mixtures to pyrolytic conditions under vacuum. Reagents are sublimated through the system and the products condensed by cold traps. In continuous liquid spray vaporization (CLSV) reagents are aerosolised through the system using a carrier gas. Here no vacuum is required, and the substrates do not have to be volatile. Reaction times are considerably reduced and can be achieved within a few milliseconds. New enabling technologies such as the Thalesnano ${ }^{\mathrm{TM}}$ Flash Pyrolysis Platform, have led to a steady uptake of these techniques. Applications include sigmatropic reactions, cycloadditions, pericyclic reactions. ${ }^{[99]}$

\subsection{Low-temperature Reactions}

Metal/halogen exchange, direct metalation, and highly exothermic reactions generally require cryogenic cooling to control temperatures efficiently. Some examples by our own group
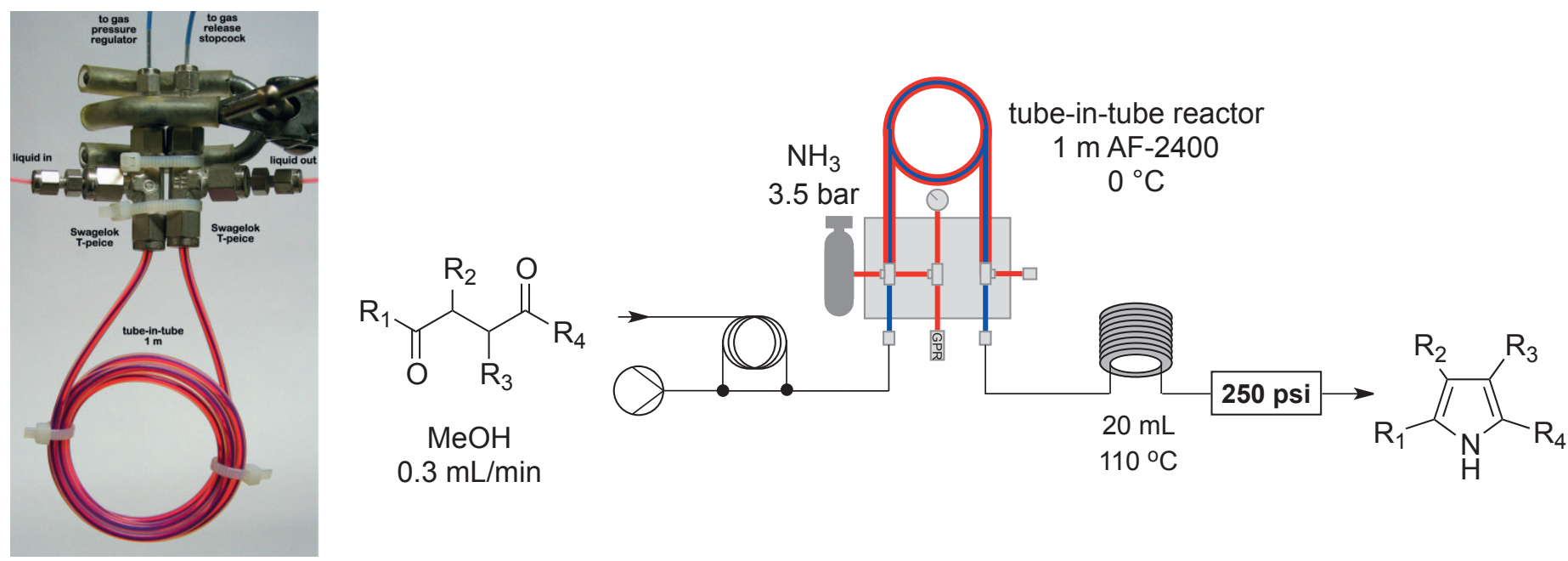

Fig. 8. Left: Tube-in-tube gas-liquid flow reactor (held in a clamp); Right: The Paal-Knorr pyrrole synthesis using tube-in-tube apparatus. Adapted from ref. [86d] with permission from The Royal Society of Chemistry. 
a

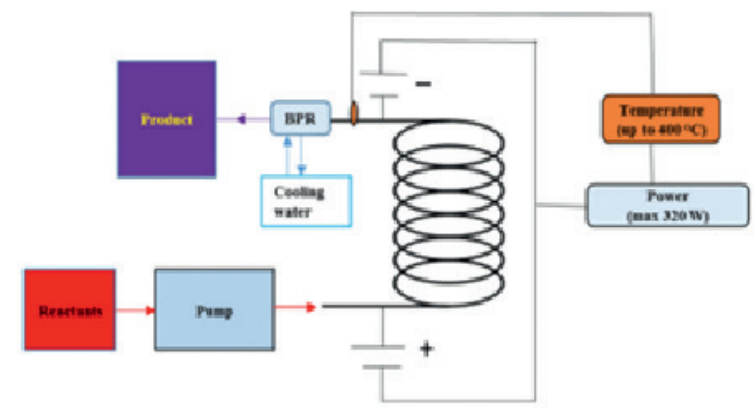

b

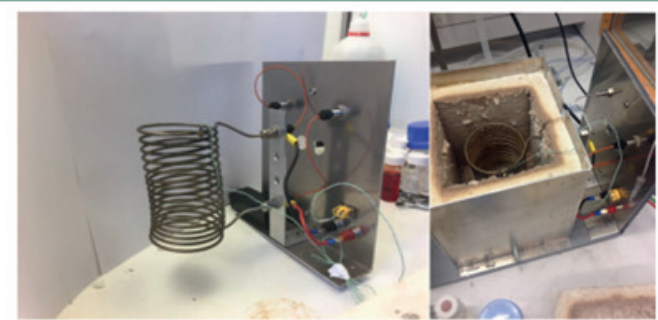

Fig. 9. a) Schematic overview of a continuous flow reactor heated by electrical potential drop which was used to achieve high reactor temperatures; b) Photograph of the reactor placed in an insulated casing. Adapted with permission from [96]. Copyright 2017 American Chemical Society.

include the first designed use of a cryo-flow device for several diastereoselective fluorination processes ${ }^{[100]}$ and low temperature pre-cooled enabling technologies. ${ }^{[10 a, c]}$

Of particular note is our synthesis of tamoxifen. ${ }^{[101]}$ In this example several organometallic reagents were used, necessitating precise temperature control of both reactor systems and mixing junctions (Fig. 10). Pre-cooling loops were deployed to ensure that temperature control was maintained at the point where reagent streams met. The ability to accurately and continuously vary the temperature range presented major benefits over traditional cooling-bath methods.

\subsection{Supercritical Fluids}

Supercritical water has found wide application in commercial effluent and waste treatment, but limited use in classical synthesis procedures. This is partly due to the engineering challenges of constructing suitable small-scale reactors, but also because of its poor selectivity under the typically aggressive oxidation conditions.

Carbon dioxide does not suffer these shortfalls and has been subject of more research interest. Several examples of optimised continuous processes that utilise supercritical $\mathrm{CO}_{2}$ reactions are known. ${ }^{[102]}$ These include photo-oxidation using singlet oxygen, ${ }^{[103]}$ continuous methylation of alcohols, ${ }^{[104]}$ the carboxymethylation optimization of dimethyl carbonate ${ }^{[105]}$ and many more.
For academic research supercritical set-ups have required large foot prints and have been custom designed. This has historically required the need to be conducted in specialised research groups. The introduction of high-temperature and -pressure systems, such as the ThalesNano Phoenix ${ }^{[89]}$ is helping to bridge this gap and enable high-temperature reactions to be conducted by less specialised groups.

\subsection{D printing}

Three-dimensional (3D) printing has steadily been gaining traction in a number of engineering and scientific disciplines. Multiple techniques exist to conduct printing, including fused deposition modelling (FDM), selective layer sintering (SLS) and sterolithography (SLG). Several recent reviews describes each of these in more detail.[106] The ready availability of printers has removed many of the barriers associated with the technology. There is now a wealth of literature and tutorials online, largely developed by the open source community, enabling individuals with little or no manufacturing experience to begin using powerful tools.

An early application of this rapid prototyping technique to fabricate a number of miniaturised fluidic reactionware using FDM printers has been reported. ${ }^{[107]}$ More recently the application of encapsulating reagents into 3D reactionware was demonstrated.[108] In this example polypropylene (PP) was chosen as the material for its chemical compatibility and relative thermal stability up to $150{ }^{\circ} \mathrm{C}$. The $3 \mathrm{D}$ build process was halted before completion to allow the addition of reagents. This research programme was expanded further through the development of a 3D reactor consisting of multiple compartments for multi-stage synthesis and purification. ${ }^{[109]}$

Perhaps the most ubiquitous use of additive technology for chemical applications has been the developments of microreactors, working towards a 'lab on a chip,' and the rapid prototyping of new reactor designs. The application of Digital Light Processing Stereolithography (DLP-SLA) has been reported recently as an attractive and inexpensive 3-D printing technique for microfluidics which offers increased printing resolution. ${ }^{[110]}$

Perfluoropolyether (PFPE) polymers are an interesting alternative for the fabrication of chemically-resistant devices. In addition to their chemical stability, they exhibit high optical transparency to visible light, have low surface energy and provide tuneable elasticity. ${ }^{[111]}$

Micro-channelled reactors are not the only targets for 3D printing. Other essential flow equipment such as syringe pumps have been fabricated using this technology. ${ }^{[112]}$ Custom-designed polypropylene reactor columns have been used to perform $\mathrm{S}_{\mathrm{N}} \mathrm{Ar}$ reactions at high temperature in DMF for intramolecular acylal cyclisation reactions in the presence of $\mathrm{BF}_{3}: \mathrm{OEt}_{2}$ in DCM. ${ }^{[113]} \mathrm{As}$ the range of materials widens it can be imagined that a $4^{\text {th }}$ dimension could be used whereby 3D printed materials can transform by themselves using heat, water, sound or vibration in to multiple configurations.
Fig. 10. Continuous-flow processing of organometallic regents using low temperature reactor to produce one therapeutic dose every five seconds of the anti-cancer drug compound tamoxifen. ${ }^{[101]}$

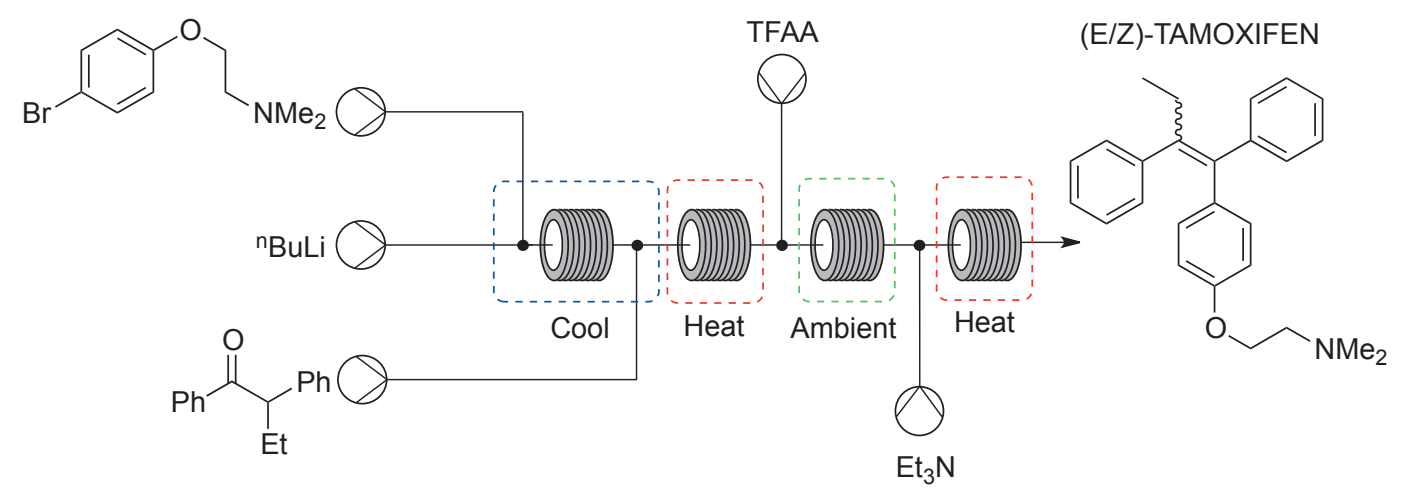


However, 3D printing techniques suffer from hurdles associated with chemical compatibility and limitations linked to pressure and temperature. We believe that these technical challenges are temporary and will be overcome as more materials become available. Recent work described the fabrication of a printed stainless-steel reactor for continuous difluoromethylation. ${ }^{[114]}$ Computational fluid dynamic (CFD) modelling was used to design a flow channel, which incorporated separate quench and cooling channels.

Another potential pitfall of $3 \mathrm{D}$ printed reactors is their short life cycles. In a world focusing on renewable sources and greener processes, 3D printing could be regarded as wasteful as components cannot be easily disassembled and re-used. Paradoxically, the process encourages a consumable culture that potentially undermines many of the gains made through continuous processes.

Additive technology is likely to continue to play a significant part in the future - particularly for the design and development of novel reactors. Other foreseeable uses included in-house fabrication of custom and consumable parts such as valves, unions and t-pieces as well as the ability to adapt/repair existing lab equipment. The availability of open source software and cloud-hosted 3D design packages such as Autodesk Fusion 360 will continue to lower the entrance barrier to this technology and provide access to a wealth of knowledge and resources usually only available to engineers. It is also foreseeable that problems will be jointly solved through a more multidisciplinary approach as the toolkits from other disciplines are used to solve more complex chemical and synthetic problems.

\section{Reaction Telescoping and Downstream Processing}

Interestingly, while the implementation of flow chemistry techniques has resulted in considerable innovation and equipment development, most of this activity has been focused on upstream events often involving single reaction steps. ${ }^{[115]}$ Product work-up often follows a traditional pathway with little thought being given to novel downstream processing tools. Yet in the vast number of organic synthesis programs, at least at the research level, the unit operations to afford clean products are at best cumbersome, time consuming and wasteful of materials. This becomes a major issue during long reaction sequences where telescoping of steps together would be a desired outcome but that the disproportional complexity of implementation becomes prohibitive.

Of vital importance is that we also do not forget the immense power of modern-day batch chemistry. It is essential, therefore, in going forward that full holistic integration of the best methods both in batch and flow are evaluated together and not treated as isolated competitive entities. ${ }^{[116]}$

One should recognize that all multi-step synthesis is challenging, requiring a detailed knowledge of mechanisms, methods and strategies that are not readily relegated to machines. The aim, therefore, is not to deliberately complicate a process but to improve it; one has to understand a molecule before you can make it.

Reaction telescoping is, therefore, a key strategy to facilitate many aspects of a synthesis, which can include reduction in solvent usage, minimizing downstream processing tasks, avoiding hazardous and unstable intermediate compound isolation and storage leading to overall faster product delivery times.

There are now many examples, which have been well reviewed ${ }^{[117]}$ of fully or partially telescoped reaction schemes under flow chemistry conditions leading to functional molecules, ${ }^{[5 b, 118]}$ including natural products. ${ }^{[119]}$

By way of a recent example the multistep synthesis of the HIV integrase inhibitor dolutegravir has been reported (Fig. 11). ${ }^{[120]}$ This example expanded the limits on continuous flow processing potential by telescoping seven steps together, producing the target material with $24 \%$ overall yield.
However, deeper analysis of many telescoped sequences on smaller scales reveal deficiencies in current methods. While good levels of experimental control are available, as are accompanying analytical methods, there is some way to go in terms of downstream processing tools. In-line evaporation ${ }^{[121]}$ or solvent switching, ${ }^{[122]}$ especially for more challenging reaction sequences $^{[123]}$ where solvent incompatibilities arise or precipitation issues cause clogging to occur, ${ }^{[124]}$ which are common problems in many multi-step procedures. ${ }^{[125]}$

Often by telescoping processes together compound mixtures can arise which, if not addressed until the final product purification stage, can prove to be insurmountable when it comes to separation. Therefore, in-line continuous separative techniques, such as Simulated Moving Bed chromatography ${ }^{[126]}$ or recently multiplexed ${ }^{[127]} \mathrm{CO}_{2}$ supercritical fluid chromatography can provide a solution. Nevertheless, these systems can be expensive to install and are therefore often tailored for more specific and demanding applications.

Practical alternatives can be found using immobilized resins to selectively scavenge by-products or impurities in-line to afford clean product streams. Indeed, this technology has been underutilized despite its obvious opportunities. Nevertheless, there is resurgent interest in the area and useful, new reviews are appearing. ${ }^{[115,128]}$

Application of the immobilized agents either as cocktail mixtures or linear combinations ${ }^{[129]}$ to remove in-line multiple undesired impurities is an attractive strategy. ${ }^{[130]}$ Likewise using a catch and release approach by capturing the desired product from a complex product stream using complimentary recognition on an immobilized format and subsequently releasing the clean product into the flow stream is a particularly useful technique for telescoping ${ }^{[131]}$ steps together during continuous flow synthesis. These methods become even more powerful when used in combination with supported reagents to effect multi-step syntheses ${ }^{[123]}$ since the spent reagent is immobilized and does not enter the flow stream but is readily recovered and, in many cases, recycled. In this way many of the traditional time and labour consuming workup methods such as chromatography, water washing, distillation and crystallization can be avoided. ${ }^{[132]}$ Improved supported reagents ${ }^{[133]}$ particularly for asymmetric transformations or higher surface loadings are in great demand.

Despite the success of these techniques many syntheses inevitably end up with a downstream liquid-liquid separation problem, which during a multi-step telescoped process can be a barrier to success.

Although membrane separation ${ }^{[134]}$ can afford one solution to the problem, particularly the very powerful Zaiput device, ${ }^{[135]}$ camera monitored ${ }^{[26]}$ or other liquid-liquid separations ${ }^{[136]}$ are now commonplace but further development of off-the-shelf modular units for downstream/in-line processing are still needed.

Telescoping multi-enzyme[74a] or multiple gas reaction steps ${ }^{[86 a]}$ together can come with their own problems but are seen as important future opportunities. Again immobilization ${ }^{[137]}$ or membrane methods ${ }^{[138]}$ using tube-in-tube reactors, ${ }^{[85,139]}$ for example, can overcome some of the issues although both these fields are ripe for further development.

As a showcase of a flow sequence with multiple gas combinations, the Pd-catalysed vinylation of aryl iodides using ethylene gas followed with the Rh-catalysed hydroformylation with $\mathrm{H}_{2}$ and $\mathrm{CO}$ to give branched aldehydes is instructive (Fig. 12). ${ }^{[86 \mathrm{~b}]}$

\section{Conclusions}

The world around us is highly digitally connected and this is accelerating discovery in many areas of science. Enhanced data sets are providing new insights and opportunities through various algorithm-driven information mining, machine learning techniques and also during high throughput experimentation. Flow 


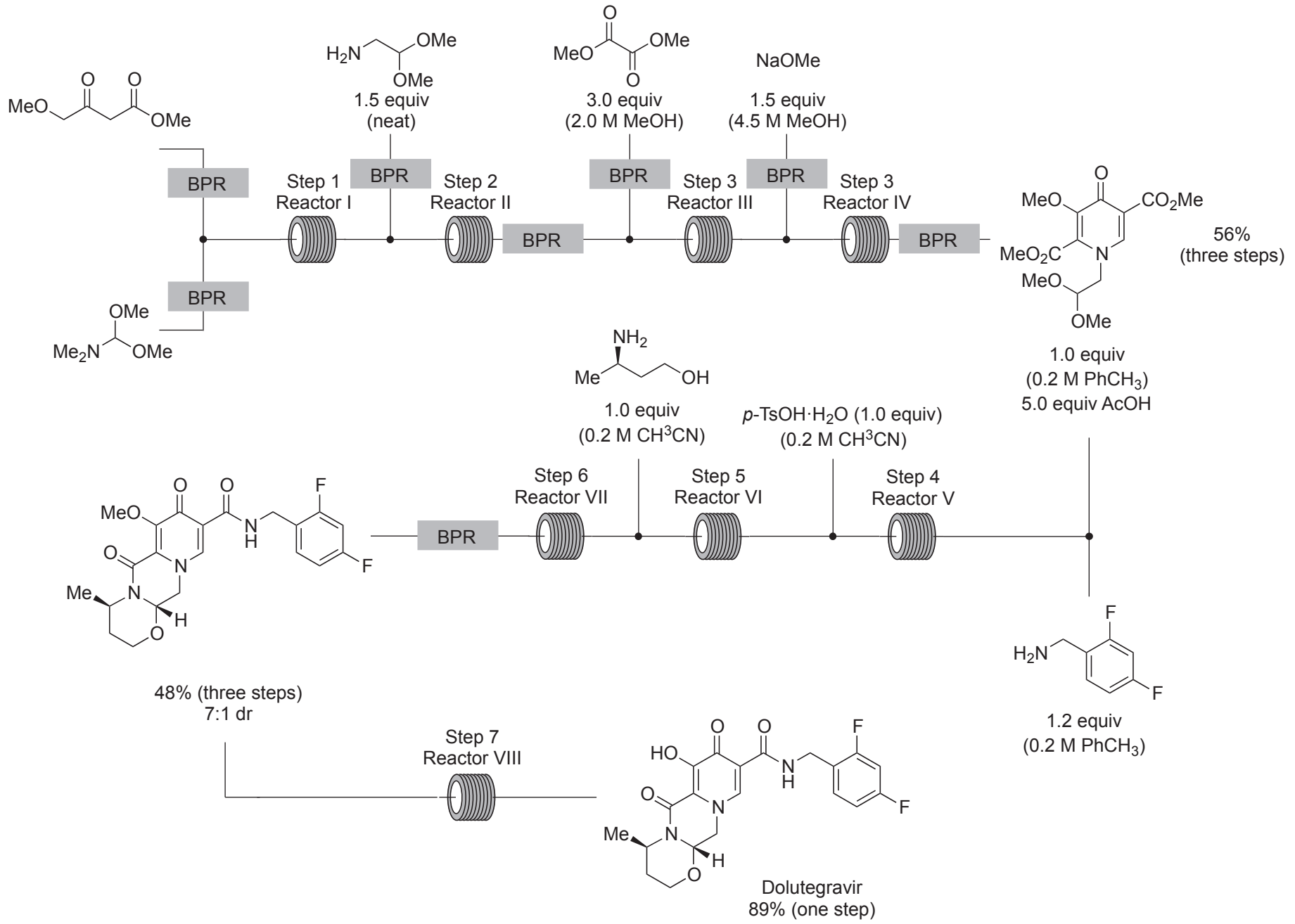

Fig. 11. The seven-step flow synthesis of dolutegravir was achieved using continuous flow chemistry techniques. ${ }^{[120]}$

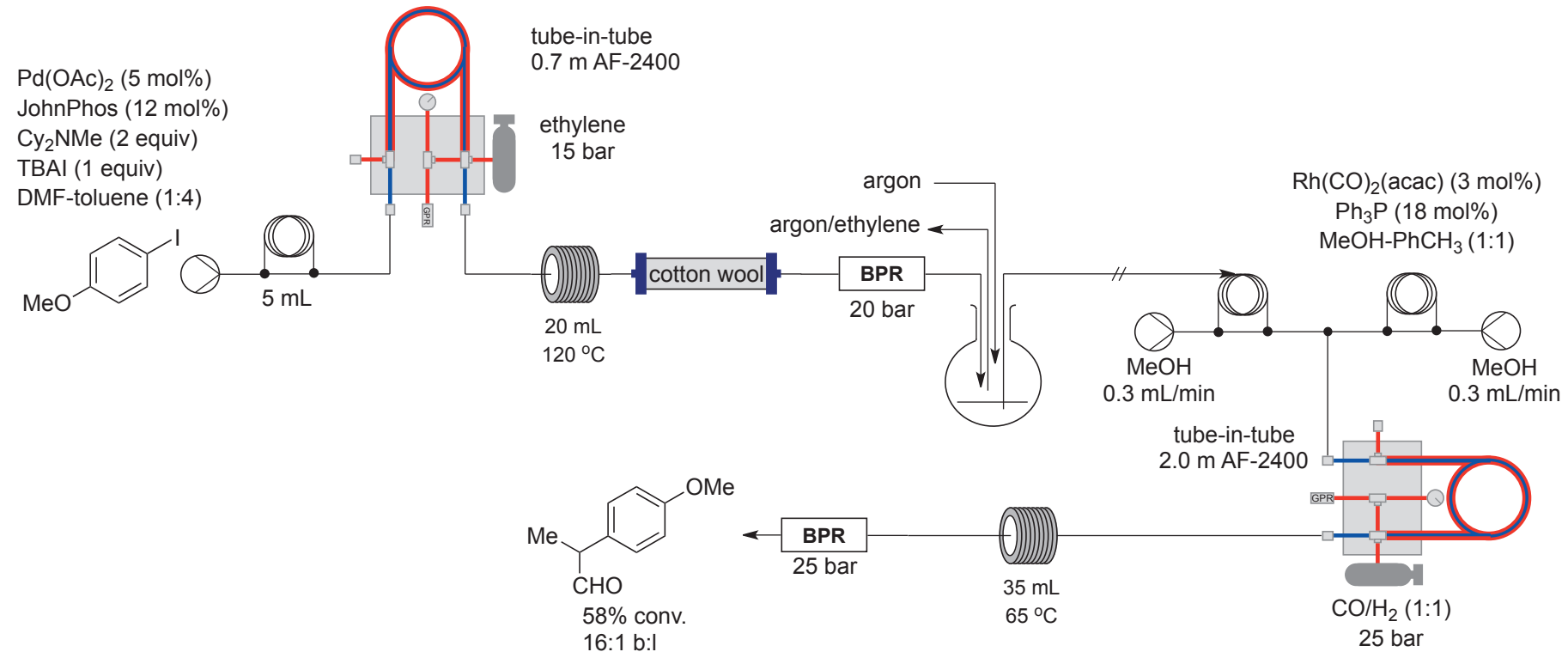

Fig. 12. A multistep, telescoped flow sequence has been reported which involves two gaseous reactions, as enabled by tube-in-tube techniques. ${ }^{[866]}$

chemistry and continuous processing methods for the assembly of our functional materials are ideally placed to benefit from these concepts. Innovation is all around us thereby increasing our skill-set and driving change to our current conventional capabilities. Future laboratories are evolving quickly to best integrate all these new ideas but there is still much to do. Downstream reaction processing is a major bottleneck that can only be solved by the discovery of new strategically important reactions and the use of inventive enabling technologies.

Going forward robots in labs will feature more commonly but they cannot replace the full capabilities of human endeavour; rather they create time for researchers to think, plan and invent new chemistries. Indeed, the amalgamation of human effort with machine-assisted and other enabling technologies will 
augment research capabilities and drive future developments in chemistry.

\section{Summary of Future Needs}

- Improved reaction telescoping methods

- Improved downstream processing tools

- New in-line solvent evaporators

- Automated liquid-liquid separators

- Increased use of microprocessors for reactor control

- More application of ML techniques

- Development of new AI algorithms

- More multi-enzyme cascades

- Improved enzyme immobilisation methods

- More intermediate scale-up tools

- Discovery of new reactions

- New self-optimisation tools

- Continued development of analytics

- Greater integration of flow and batch methods

- Increased use of robots

- Increased use of AR and VR techniques

- Wider use of image capturing and data-mining techniques

- Adoption of holistic systems planning

- Voice-controlled AI

- Use of compartmentalisation technologies

\section{Acknowledgements}

The authors gratefully acknowledge financial support from Pfizer (Y.C.), Dstl (O.M.) and the H2020-FET OPEN-2016-2017 Programme of the European commission (D.E.F., S.V.L.;grant agreement number:737266-ONE FLOW)

Received: April 15, 2019

[1] a) D. E. Fitzpatrick, C. Battilocchio, S. V. Ley, ACS Cent. Sci. 2016, 2 , 131, DOI: 10.1021/acscentsci.6b00015; b) D. E. Fitzpatrick, S. V. Ley, Tetrahedron 2018, 74, 3087, DOI: 10.1016/j.tet.2017.08.050; c) A. R. Bogdan, A. W. Dombrowski, J. Med. Chem. 2019, DOI: 10.1021/acs. jmedchem. $8 \mathrm{~b} 01760$

[2] a) S. V. Ley, D. E. Fitzpatrick, R. J. Ingham, R. M. Myers, Angew. Chem. Int. Ed. 2015, 54, 3449, DOI: 10.1002/anie.201410744; b) S. V. Ley, D. E. Fitzpatrick, R. M. Myers, C. Battilocchio, R. J. Ingham, Angew. Chem. Int. Ed. 2015, 54, 10122, DOI: 10.1002/anie.201501618.

[3] R. J. Ingham, C. Battilocchio, D. E. Fitzpatrick, E. Sliwinski, J. M. Hawkins, S. V. Ley, Angew. Chem. Int. Ed. 2015, 54, 144, DOI: 10.1002/ anie. 201409356

[4] S. L. Lee, T. F. O'Connor, X. Yang, C. N. Cruz, S. Chatterjee, R. D. Madurawe, C. M. V. Moore, L. X. Yu, J. Woodcock, J. Pharm. Innov. 2015, 10, 191, DOI: $10.1007 / \mathrm{s} 12247-015-9215-8$.

[5] a) J. Wegner, S. Ceylan, A. Kirschning, Adv. Synth. Catal. 2012, 354, 17, DOI: 10.1002/adsc.201100584; b) M. Baumann, I. R. Baxendale, S. V. Ley, Mol. Divers. 2011, 15, 613, DOI: 10.1007/s11030-010-9282-1.

[6] C. Battilocchio, F. Bosica, S. M. Rowe, B. L. Abreu, E. Godineau, M Lehmann, S. V. Ley, Org. Process Res. Dev. 2017, 21, 1588, DOI: 10.1021/ acs.oprd.7b00229.

[7] a) M. Movsisyan, E. I. P. Delbeke, J. K. E. T. Berton, C. Battilocchio, S. V. Ley, C. V. Stevens, Chem. Soc. Rev. 2016, 45, 4892, DOI: 10.1039/ C5CS00902B. b) B. Gutmann, D. Cantillo, C. O. Kappe, Angew. Chem. Int. Ed. 2015, 54, 6688, DOI: 10.1002/anie.201409318; c) M. Baumann, I. R. Baxendale, Beilstein J. Org. Chem. 2015, 11, 1194, DOI: 10.3762/ bjoc. 11.134

[8] a) M. Brzozowski, M. O'Brien, S. V. Ley, A. Polyzos, Acc. Chem. Res. 2015 48, 349, DOI: 10.1021/ar500359m; b) C. J. Mallia, I. R. Baxendale, Org. Process Res. Dev. 2016, 20, 327, DOI: 10.1021/acs.oprd.5b00222; c) A Günther, K. F. Jensen, Lab Chip 2006, 6, 1487, DOI: 10.1039/B609851G; d) A. Gavriilidis, A. Constantinou, K. Hellgardt, K. K. Hii, G. J. Hutchings, G. L. Brett, S. Kuhn, S. P. Marsden, React. Chem. Eng. 2016, 1, 595, DOI: 10.1039/C6RE00155F

[9] a) D. E. Fitzpatrick, C. Battilocchio, S. V. Ley, Org. Process Res. Dev. 2016 20, 386, DOI: 10.1021/acs.oprd.5b00313; b) V. Sans, L. Cronin, Chem. Soc. Rev. 2016, 45, 2032, DOI: 10.1039/C5CS00793C; c) K. Poscharny, D. C. Fabry, S. Heddrich, E. Sugiono, M. A. Liauw, M. Rueping, Tetrahedron 2018, 74, 3171, DOI: 10.1016/j.tet.2018.04.019; d) D. C. Fabry, E. Sugiono, M. Rueping, Isr. J. Chem. 2014, 54, 341, DOI: 10.1002/ijch.201300080.
[10] a) D. L. Browne, M. Baumann, B. H. Harji, I. R. Baxendale, S. V. Ley, Org. Lett. 2011, 13, 3312, DOI: 10.1021/ol2010006; b) J. A. Newby, L. Huck, D. W. Blaylock, P. M. Witt, S. V. Ley, D. L. Browne, Chem. Eur. J. 2014, 20, 263, DOI: 10.1002/chem.201303736; c) D. L. Browne, B. H. Harji, S. V. Ley, Chem. Eng. Technol. 2013, 36, 959, DOI: 10.1002/ ceat.201200581; d) Z. Qian, I. R. Baxendale, S. V. Ley, Synlett 2010, 2010, 505, DOI: 10.1055/s-0029-1219358; e) A. R. Bogdan, M. Charaschanya, A. W. Dombrowski, Y. Wang, S. W. Djuric, Org. Lett. 2016, 18, 1732, DOI: 10.1021/acs.orglett.6b00378.

[11] T. Ouchi, C. Battilocchio, J. M. Hawkins, S. V. Ley, Org. Process Res. Dev. 2014, 18, 1560, DOI: 10.1021/op500208j.

[12] a) D. E. Fitzpatrick, T. Maujean, A. C. Evans, S. V. Ley, Angew. Chem. Int. Ed. 2018, 57, 15128, DOI: 10.1002/anie.201809080; b) D. L. Browne, B. J. Deadman, R. Ashe, I. R. Baxendale, S. V. Ley, Org. Process Res. Dev. 2011, 15, 693, DOI: $10.1021 / \mathrm{op} 2000223$.

[13] a) M. B. Plutschack, B. Pieber, K. Gilmore, P. H. Seeberger, Chem. Rev. 2017, 117, 11796, DOI: 10.1021/acs.chemrev.7b00183. b) R. L. Hartman, J. P. McMullen, K. F. Jensen, Angew. Chem. Int. Ed. 2011, 50, 7502, DOI: 10.1002/anie.201004637.

[14] G. Jas, A. Kirschning, Chem. Eur. J. 2003, 9, 5708, DOI: 10.1002/ chem.200305212.

[15] A. E. Williamson, P. M. Ylioja, M. N. Robertson, Y. Antonova-Koch, V. Avery, J. B. Baell, H. Batchu, S. Batra, J. N. Burrows, S. Bhattacharyya, F. Calderon, S. A. Charman, J. Clark, B. Crespo, M. Dean, S. L. Debbert, M. Delves, A. S. M. Dennis, F. Deroose, S. Duffy, S. Fletcher, G. Giaever, I. Hallyburton, F.-J. Gamo, M. Gebbia, R. K. Guy, Z. Hungerford, K. Kirk, M. J. Lafuente-Monasterio, A. Lee, S. Meister, C. Nislow, J. P. Overington, G. Papadatos, L. Patiny, J. Pham, S. A. Ralph, A. Ruecker, E. Ryan, C. Southan, K. Srivastava, C. Swain, M. J. Tarnowski, P. Thomson, P. Turner, I. M. Wallace, T. N. C. Wells, K. White, L. White, P. Willis, E. A. Winzeler, S. Wittlin, M. H. Todd, ACS Cent. Sci. 2016, 2, 687, DOI: 10.1021/ acscentsci.6b00086.

[16] R. A. Skilton, A. J. Parrott, M. W. George, M. Poliakoff, R. A. Bourne, Appl. Spectrosc. 2013, 67, 1127, DOI: 10.1366/13-06999.

[17] a) M. A. Kabeshov, É. Śliwiński, D. E. Fitzpatrick, B. Musio, J. A. Newby, W. D. W. Blaylock, S. V. Ley, Chem. Comm. 2015, 51, 7172, DOI: 10.1039/ C5CC00782H; b) C. W. Coley, R. Barzilay, T. S. Jaakkola, W. H. Green, K. F. Jensen, ACS Cent. Sci. 2017, 3, 434, DOI: 10.1021/acscentsci.7b00064.

[18] M. O'Brien, P. Koos, D. L. Browne, S. V. Ley, Org. Biomol. Chem. 2012, 10, 7031, DOI: $10.1039 / \mathrm{C} 2 \mathrm{OB} 25912 \mathrm{E}$.

[19] S. V. Ley, Angew. Chem. Int. Ed. 2018, 57, 5182, DOI: 10.1002/ anie. 201802383 .

[20] M. Zheng, M. P. Waller, J. Mol. Graph. Model. 2017, 73, 18, DOI: 10.1016/j. jmgm.2017.01.019.

[21] S. Yang, B. Mei, X. Yue, J. Chem. Educ. 2018, 95, 1060, DOI: 10.1021/acs. jchemed.8b00017.

[22] B. Musio, F. Mariani, E. P. Śliwiński, M. A. Kabeshov, H. Odajima, S. V. Ley, Synthesis 2016, 48, 3515, DOI: 10.1055/s-0035-1562579.

[23] S. Kim, M. A. Nussbaum, J. L. Gabbard, IIE Trans. Occup. 2016, 4, 253, DOI: $10.1080 / 21577323.2016 .1214635$.

[24] Y. Yang, W. Gao, Chem. Soc. Rev. 2019, DOI: 10.1039/C7CS00730B

[25] S. V. Ley, D. E. Fitzpatrick, R. J. Ingham, N. Nikbin, Beilstein Mag. 2015, 1, No. 2, DOI: $10.3762 /$ bmag.2.

[26] S. V. Ley, R. J. Ingham, M. O'Brien, D. L. Browne, Beilstein J. Org. Chem. 2013, 9, 1051, DOI: 10.3762/bjoc.9.118.

[27] S. V. Ley, I. R. Baxendale, CHIMIA 2008, 62, 162, DOI: 10.2533/chimia.2008.162.

[28] Y.-F. Lin, Y.-H. Wu, S.-M. Lai, Ind. Eng. Chem. Res. 2012, 51, 10778, DOI: 10.1021/ie301280c.

[29] M. O'Brien, J. CO2 Util. 2017, 21, 580, DOI: 10.1016/j.jcou.2017.08.020.

[30] M. O'Brien, D. A. Cooper, J. Dolan, Tetrahedron Lett. 2017, 58, 829, DOI: 10.1016/j.tetlet.2017.01.029.

[31] a) M. O'Brien, A. Hall, J. Schrauwen, J. van der Made, Tetrahedron 2018 , 74, 3152, DOI: 10.1016/j.tet.2018.02.043; b) M. O'Brien, L. Konings, M. Martin, J. Heap, Tetrahedron Lett. 2017, 58, 2409, DOI: 10.1016/j.tetlet.2017.05.008.

[32] R. J. Ingham, C. Battilocchio, J. M. Hawkins, S. V. Ley, Beilstein J. Org. Chem. 2014, 10, 641, DOI: 10.3762/bjoc.10.56.

[33] P. L. Urban, Angew. Chem. Int. Ed. 2018, 57, 11074, DOI: 10.1002/ anie.201803878.

[34] K. T. Butler, D. W. Davies, H. Cartwright, O. Isayev, A. Walsh, Nature 2018, 559, 547, DOI: $10.1038 / \mathrm{s} 41586-018-0337-2$.

[35] J. Schmidhuber, Neural Networks 2015, 61, 85, DOI: 10.1016/j.neunet.2014.09.003.

[36] F. Häse, I. Fdez. Galván, A. Aspuru-Guzik, R. Lindh, M. Vacher, Chem. Sci. 2019, 10, 2298, DOI: 10.1039/C8SC04516J.

[37] a) H. Chen, O. Engkvist, Y. Wang, M. Olivecrona, T. Blaschke, Drug Discov. Today 2018, 23, 1241, DOI: 10.1016/j.drudis.2018.01.039; b) G. B. Goh, N. O. Hodas, A. Vishnu, J. Comput. Chem. 2017, 38, 1291, DOI: 10.1002/jcc.24764; c) E. Gawehn, J. A. Hiss, G. Schneider, Mol. Inform. 
2016, 35, 3, DOI: 10.1002/minf.201501008; d) A. Lavecchia, Drug Discov. Today 2015, 20, 318, DOI: 10.1016/j.drudis.2014.10.012.

[38] R. Grainger, T. D. Heightman, S. V. Ley, F. Lima, C. N. Johnson, Chem. Sci. 2019, 10, 2264, DOI: 10.1039/C8SC04789H.

[39] C. W. Coley, W. H. Green, K. F. Jensen, Acc. Chem. Res. 2018, 51, 1281, DOI: $10.1021 /$ acs.accounts.8b00087.

[40] S. Szymkuć, E. P. Gajewska, T. Klucznik, K. Molga, P. Dittwald, M. Startek, M. Bajczyk, B. A. Grzybowski, Angew. Chem. Int. Ed. 2016, 55, 5904, DOI: 10.1002/anie.201506101.

[41] a) K. D. Collins, T. Gensch, F. Glorius, Nat. Chem. 2014, 6, 859, DOI: 10.1038/nchem.2062; b) A. McNally, C. K. Prier, D. W. C. MacMillan, Science 2011, 334, 1114, DOI: 10.1126/science.1213920.

[42] J. M. Granda, L. Donina, V. Dragone, D.-L. Long, L. Cronin, Nature 2018 559, 377, DOI: 10.1038/s41586-018-0307-8.

[43] Y. Wang, S. Shaabani, M. Ahmadianmoghaddam, L. Gao, R. Xu, K. Kurpiewska, J. Kalinowska-Tluscik, J. Olechno, R. Ellson, M. Kossenjans, V. Helan, M. Groves, A. Dömling, ACS Cent. Sci. 2019, 5, 451, DOI: 10.1021/acscentsci.8b00782.

[44] a) D. T. Ahneman, J. G. Estrada, S. Lin, S. D. Dreher, A. G. Doyle, Science 2018, 360, 186, DOI: 10.1126/science.aar5169; b) H. Gao, T. J. Struble, C. W. Coley, Y. Wang, W. H. Green, K. F. Jensen, ACS Cent. Sci. 2018, 4, 1465, DOI: $10.1021 /$ acscentsci.8b00357.

[45] K. D. Collins, F. Glorius, Nat. Chem. 2013, 5, 597, DOI: 10.1038/ nchem.1669.

[46] C. Houben, A. A. Lapkin, Curr. Opin. Chem. Eng. 2015, 9, 1, DOI: 10.1016/j.coche.2015.07.001.

[47] a) B. J. Reizman, K. F. Jensen, Acc. Chem. Res. 2016, 49, 1786, DOI: 10.1021/acs.accounts.6b00261; b) D. C. Fabry, E. Sugiono, M. Rueping, React. Chem. Eng, 2016, 1, 129, DOI: 10.1039/C5RE00038F.

[48] A. M. Schweidtmann, A. D. Clayton, N. Holmes, E. Bradford, R. A. Bourne, A. A. Lapkin, Chem. Eng. J. 2018, 352, 277, DOI: 10.1016/j. cej.2018.07.031.

[49] M. Rubens, J. H. Vrijsen, J. Laun, T. Junkers, Angew. Chem. Int. Ed. 2019, 58, 3183, DOI: 10.1002/anie.201810384

[50] A.-C. Bédard, A. Adamo, K. C. Aroh, M. G. Russell, A. A. Bedermann, J. Torosian, B. Yue, K. F. Jensen, T. F. Jamison, Science 2018, 361, 1220 , DOI: $10.1126 /$ science.aat0650.

[51] S. Chow, S. Liver, A. Nelson, Nat. Rev. Chem. 2018, 2, 174, DOI: 10.1038/ s41570-018-0025-7.

[52] a) A. Baranczak, N. P. Tu, J. Marjanovic, P. A. Searle, A. Vasudevan, S. W. Djuric, ACS Med. Chem. Lett. 2017, 8, 461, DOI: 10.1021/ acsmedchemlett.7b00054; b) D. Perera, J. W. Tucker, S. Brahmbhatt, C. J. Helal, A. Chong, W. Farrell, P. Richardson, N. W. Sach, Science 2018 359, 429, DOI: 10.1126/science.aap9112; c) L. Guetzoyan, N. Nikbin, I. R Baxendale, S. V. Ley, Chem. Sci. 2013, 4, 764, DOI: 10.1039/C2SC21850J.

[53] A. B. Beeler, S. R. Corning, in 'Photochemistry: Volume 43', Vol. 43, The Royal Society of Chemistry, 2016, p. 173, DOI: $10.1039 / 9781782622772-$ 00173.

[54] a) F. Politano, G. Oksdath-Mansilla, Org. Process Res. Dev. 2018, 22, 1045 , DOI: 10.1021/acs.oprd.8b00213; b) Z. J. Garlets, J. D. Nguyen, C. R. J. Stephenson, Isr. J. Chem. 2014, 54, 351, DOI: 10.1002/ijch.201300136; c) A. Visan, J. R. van Ommen, M. T. Kreutzer, R. G. H. Lammertink, Ind. Eng. Chem. Res. 2019, DOI: 10.1021/acs.iecr.9b00381.

[55] K. I. Booker-Milburn, T. Noël, ChemPhotoChem 2018, 2, 830, DOI: $10.1002 /$ cptc. 201800184 .

[56] M. Czarnecki, P. Wessig, Org. Process Res. Dev. 2018, 22, 1823, DOI: 10.1021/acs.oprd.8b00353.

[57] F. Guba, Ü. Tastan, K. Gugeler, M. Buntrock, T. Rommel, D. Ziegenbalg, Chem. Ing. Tech 2019, 91, 17, DOI: doi:10.1002/cite.201800035.

[58] R. C. McAtee, E. J. McClain, C. R. J. Stephenson, Trends Chem. 2019 DOI: $10.1016 /$ j.trechm.2019.01.008.

[59] K. C. Harper, E. G. Moschetta, S. V. Bordawekar, S. J. Wittenberger, ACS Cent. Sci. 2019, 5, 109, DOI: 10.1021/acscentsci.8b00728.

[60] D. M. Schultz, T. P. Yoon, Science 2014, 343, 1239176, DOI: 10.1126/sci ence. 1239176.

[61] D. Cambié, T. Noël, Top. Curr. Chem. 2018, 376, 45, DOI: 10.1007/s41061018-0223-2.

[62] a) F. Zhao, D. Cambié, J. Janse, E. W. Wieland, K. P. L. Kuijpers, V. Hessel, M. G. Debije, T. Noël, ACS Sustain. Chem. Eng. 2018, 6, 422, DOI: 10.1021/acssuschemeng.7b02687; b) F. Zhao, D. Cambié, V. Hessel, M. G. Debije, T. Noël, Green Chem. 2018, 20, 2459, DOI: 10.1039/C8GC00613J.

[63] D. Cambié, F. Zhao, V. Hessel, M. G. Debije, T. Noël, Angew. Chem. Int. Ed. 2017, 56, 1050, DOI: 10.1002/anie.201611101.

[64] G. I. Ioannou, T. Montagnon, D. Kalaitzakis, S. A. Pergantis, G. Vassilikogiannakis, Org. Biomol. Chem. 2017, 15, 10151, DOI: 10.1039/ C7OB02557B

[65] X. Zhu, W. Zhang, Q. Lin, M. Ye, L. Xue, J. Liu, Y. Wang, H. Cheng, ACS Sustain. Chem. Eng. 2019, DOI: 10.1021/acssuschemeng.9b00427.

[66] C. J. Kong, D. Fisher, B. K. Desai, Y. Yang, S. Ahmad, K. Belecki, B. F. Gupton, Bioorg. Med. Chem. 2017, 25, 6203, DOI: 10.1016/j. bmc.2017.07.004
[67] J. D. Williams, M. Nakano, R. Gérardy, J. A. Rincón, Ó. de Frutos, C. Mateos, J.-C. M. Monbaliu, C. O. Kappe, Org. Process Res. Dev. 2019, 23, 78, DOI: 10.1021/acs.oprd.8b00375.

[68] a) E. V. Kondratenko, G. Mul, J. Baltrusaitis, G. O. Larrazábal, J. PérezRamírez, Energ Environ. Sci. 2013, 6, 3112, DOI: 10.1039/C3EE41272E; b) J.-B. Vennekoetter, R. Sengpiel, M. Wessling, Chem. Eng. J. 2019, 364, 89, DOI: 10.1016/j.cej.2019.01.045

[69] a) M. Yan, Y. Kawamata, P. S. Baran, Chem. Rev. 2017, 117, 13230 DOI: 10.1021/acs.chemrev.7b00397; b) T. Fuchigami, S. Inagi, 'Organic Electrosynthesis', John Wiley \& Sons Ltd, Chichester, 2015.

[70] a) B. R. Babu, P. Venkatesan, R. Kanimozhi, C. A. Basha, J. Environ. Sci. Heal. A 2009, 44, 985, DOI: 10.1080/10934520902996880; b) O. Ganzenko, D. Huguenot, E. D. van Hullebusch, G. Esposito, M. A. Oturan, Environ. Sci. Pollut. R. 2014, 21, 8493, DOI: 10.1007/s11356-014-2770-6; c) N. M. P. Queiroz, I. Sirés, C. L. P. S. Zanta, J. Tonholo, E. Brillas, Sep. Purif. Technol. 2019, 216, 65, DOI: 10.1016/j.seppur.2019.01.069; d) M. A. Kabeshov, B. Musio, P. R. D. Murray, D. L. Browne, S. V. Ley, Org. Lett. 2014, 16, 4618, DOI: 10.1021/ol502201d.

[71] a) K. Watts, A. Baker, T. Wirth, J. Flow Chem. 2014, 4, 2, DOI: 10.1556/ jfc-d-13-00030; b) D. Pletcher, R. A. Green, R. C. D. Brown, Chem. Rev. 2018, 118, 4573, DOI: 10.1021/acs.chemrev.7b00360.

[72] a) G. Laudadio, W. de Smet, L. Struik, Y. Cao, T. Noël, J. Flow Chem. 2018, 8, 157, DOI: 10.1007/s41981-018-0024-3; b) Y. Cao, T. Noël, Org. Process Res. Dev. 2019, 23, 403, DOI: 10.1021/acs.oprd.8b00428.

[73] a) C. Wang, L. Yue, S. Wang, Y. Pu, X. Zhang, X. Hao, W. Wang, S. Chen, J. Phys. Chem. C 2018, 122, 26454, DOI: 10.1021/acs.jpcc.8b08232; b) M. J. Kim, M. A. Cruz, F. Yang, B. J. Wiley, Curr. Opin. Electrochem. 2019, DOI: 10.1016/j.coelec.2019.03.005; c) L. F. Arenas, C. Ponce de León, F. C. Walsh, Curr. Opin. Electrochem. 2019, 16, 1, DOI: 10.1016/j. coelec.2019.02.002.

[74] a) R. Yuryev, S. Strompen, A. Liese, Beilstein J. Org. Chem. 2011, 7, 1449, DOI: 10.3762/bjoc.7.169; b) R. Karande, A. Schmid, K. Buehler, Org. Process Res. Dev. 2016, 20, 361, DOI: 10.1021/acs.oprd.5b00352; c) L. Tamborini, P. Fernandes, F. Paradisi, F. Molinari, Trends Biotechnol. 2018, 36, 73, DOI: 10.1016/j.tibtech.2017.09.005.

[75] a) A. A. Homaei, R. Sariri, F. Vianello, R. Stevanato, J. Chem. Bio. 2013, 6, 185, DOI: 10.1007/s12154-013-0102-9; b) M. P. Thompson, I. Peñafiel, S. C. Cosgrove, N. J. Turner, Org. Process Res. Dev. 2019, 23, 9, DOI: 10.1021/acs.oprd.8b00305.

[76] K. F. Schilke, K. L. Wilson, T. Cantrell, G. Corti, D. N. McIlroy, C. Kelly, Biotechnol. Progr. 2010, 26, 1597, DOI: 10.1002/btpr.476.

[77] M. P. Thompson, S. R. Derrington, R. S. Heath, J. L. Porter, J. MangasSanchez, P. N. Devine, M. D. Truppo, N. J. Turner, Tetrahedron 2019, 75, 327, DOI: 10.1016/j.tet.2018.12.004.

[78] a) M. M. E. Delville, K. Koch, J. C. M. van Hest, F. P. J. T. Rutjes, Org. Biomol. Chem. 2015, 13, 1634, DOI: 10.1039/C4OB02128B; b) A. Brahma, B. Musio, U. Ismayilova, N. Nikbin, S. B. Kamptmann, P. Siegert, G. E. Jeromin, S. V. Ley, M. Pohl, Synlett 2016, 27, 262, DOI: 10.1055/s0035-1560644; c) J. Döbber, T. Gerlach, H. Offermann, D. Rother, M. Pohl, Green Chem. 2018, 20, 544, DOI: 10.1039/C7GC03225K.

[79] a) P. Gruber, M. P. C. Marques, B. O'Sullivan, F. Baganz, R. Wohlgemuth, N. Szita, Biotechnol. J. 2017, 12, DOI: 10.1002/biot.201700030; b) S. Gandomkar, A. Żądło-Dobrowolska, W. Kroutil, ChemCatChem 2019, 11, 225, DOI: $10.1002 /$ cctc. 201801063 .

[80] M. Hamano, K. D. Nagy, K. F. Jensen, Chem. Comm. 2012, 48, 2086, DOI: 10.1039/C2CC17123F.

[81] M. N. Siddiquee, A. de Klerk, N. Nazemifard, React. Chem. Eng. 2016, 1, 418, DOI: 10.1039/C6RE00010J.

[82] G. I. Ioannou, T. Montagnon, D. Kalaitzakis, S. A. Pergantis, G. Vassilikogiannakis, ChemPhotoChem 2017, 1, 173, DOI: 10.1002/ cptc. 201600054

[83] M. Zanfir, X. Sun, A. Gavriilidis, Ind. Eng. Chem. Res. 2008, 47, 8995, DOI: $10.1021 / \mathrm{ie} 071653 \mathrm{~s}$

[84] Q. Deng, R. Shen, R. Ding, L. Zhang, Adv. Synth. Catal. 2014, 356, 2931, DOI: 10.1002 adsc.201400560.

[85] M. O'Brien, I. R. Baxendale, S. V. Ley, Org. Lett. 2010, 12, 1596, DOI: $10.1021 / 01100322 \mathrm{t}$

[86] a) U. Gross, P. Koos, M. O’Brien, A. Polyzos, S. V. Ley, Eur. J. Org. Chem. 2014, 2014, 6418, DOI: 10.1002/ejoc.201402804; b) S. Kasinathan, S. L. Bourne, P. Tolstoy, P. Koos, M. O’Brien, R. W. Bates, I. R. Baxendale, S. V. Ley, Synlett 2011, 2011, 2648, DOI: 10.1055/s-0031-1289292; c) K. Skowerski, S. J. Czarnocki, P. Knapkiewicz, ChemSusChem 2014, 7 , 536, DOI: 10.1002/cssc.201300829; d) P. B. Cranwell, M. O’Brien, D. L. Browne, P. Koos, A. Polyzos, M. Peña-López, S. V. Ley, Org. Biomol. Chem. 2012, 10, 5774, DOI: 10.1039/C2OB25407G.

[87] T. Razzaq, C. O. Kappe, Chem. Asian. J. 2010, 5, 1274, DOI: 10.1002/ asia.201000010.

[88] R. J. Sullivan, S. G. Newman, in 'Flow Chemistry for the Synthesis of Heterocycles', Eds. U. K. Sharma, E. V. Van der Eycken, Springer International Publishing, Cham, 2018, p. 161, DOI: 10.1007/7081_2018_18. 
[89] T. Ouchi, R. J. Mutton, V. Rojas, D. E. Fitzpatrick, D. G. Cork, C. Battilocchio, S. V. Ley, ACS Sustain. Chem. Eng. 2016, 4, 1912, DOI: 10.1021/acssuschemeng.6b00287.

[90] R. Labes, C. Mateos, C. Battilocchio, Y. Chen, P. Dingwall, G. R. Cumming, J. A. Rincón, M. J. Nieves-Remacha, S. V. Ley, Green Chem. 2019, 21, 59 , DOI: 10.1039/C8GC03328E.

[91] B. Li, R. Li, P. Dorff, J. C. McWilliams, R. M. Guinn, S. M. Guinness, L. Han, K. Wang, S. Yu, J. Org. Chem. 2019, DOI: 10.1021/acs.joc.8b02909.

[92] J. Tsoung, Y. Wang, S. W. Djuric, React. Chem. Eng, 2017, 2, 458, DOI: 10.1039/C7RE00058H

[93] H. Seo, A.-C. Bédard, W. P. Chen, R. W. Hicklin, A. Alabugin, T. F. Jamison, Tetrahedron 2018, 74, 3124, DOI: 10.1016/j.tet.2017.11.068.

[94] H. Roohi, M. Rajabi, Org. Process Res. Dev. 2018, 22, 136, DOI: 10.1021/ acs.oprd.7b00284

[95] E. V. Bukovsky, N. J. DeWeerd, S. H. Strauss, O. V. Boltalina, J. Fluorine Chem. 2018, 210, 56, DOI: 10.1016/j.jfluchem.2018.01.012.

[96] A. Adeyemi, J. Bergman, J. Brånalt, J. Sävmarker, M. Larhed, Org. Process Res. Dev. 2017, 21, 947, DOI: 10.1021/acs.oprd.7b00063.

[97] a) Á. Tajti, N. Tóth, E. Bálint, G. Keglevich, J. Flow Chem. 2018, 8, 11 DOI: 10.1007/s41981-018-0001-x; b) I. R. Baxendale, C. Hornung, S. V. Ley, J. d. M. M. Molina, A. Wikström, Aust. J. Chem. 2013, 66, 131, DOI: $10.1071 / \mathrm{CH} 12365$.

[98] D. Cantillo, H. Sheibani, C. O. Kappe, J. Org. Chem. 2012, 77, 2463, DOI: 10.1021/jo3001645.

[99] a) L. C. Lengyel, G. Sipos, T. Sipôcz, T. Vágó, G. Dormán, J. Gerencsér, G Makara, F. Darvas, Org. Process Res. Dev. 2015, 19, 399, DOI: 10.1021/ op500354z; b) S. Kumar, V. Kumar, S. P. Singh, in 'Pericyclic Reactions', Eds. S. Kumar, V. Kumar, S. P. Singh, Academic Press, 2016, p. 77, DOI: 10.1016/B978-0-12-803640-2.00003-8.

[100] K. Nakayama, D. L. Browne, I. R. Baxendale, S. V. Ley, Synlett 2013, 24, 1298, DOI: $10.1055 / \mathrm{s}-0033-1338455$.

[101] P. R. D. Murray, D. L. Browne, J. C. Pastre, C. Butters, D. Guthrie, S. V. Ley, Org. Process Res. Dev. 2013, 17, 1192, DOI: 10.1021/op4001548.

[102] a) R. A. Skilton, R. A. Bourne, Z. Amara, R. Horvath, J. Jin, M. J. Scully, E. Streng, S. L. Y. Tang, P. A. Summers, J. Wang, E. Pérez, N. Asfaw, G. L. P. Aydos, J. Dupont, G. Comak, M. W. George, M. Poliakoff, Nat. Chem. 2015, 7, 1, DOI: 10.1038/nchem.2143; b) X. Han, M. Poliakoff, Chem. Soc. Rev. 2012, 41, 1428, DOI: 10.1039/C2CS15314A.

[103] a) R. A. Bourne, X. Han, M. Poliakoff, M. W. George, Angew. Chem. Int. Ed. 2009, 48, 5322, DOI: 10.1002/anie.200901731; b) J. F. B. Hall, R. A Bourne, X. Han, J. H. Earley, M. Poliakoff, M. W. George, Green Chem. 2013, 15, 177, DOI: 10.1039/C2GC36711D.

[104] R. A. Bourne, R. A. Skilton, A. J. Parrott, D. J. Irvine, M. Poliakoff, Org. Process Res. Dev. 2011, 15, 932, DOI: 10.1021/op200109t.

[105] A. J. Parrott, R. A. Bourne, G. R. Akien, D. J. Irvine, M. Poliakoff, Angew. Chem. Int. Ed. 2011, 50, 3788, DOI: 10.1002/anie.201100412.

[106] a) D.-H. Ko, K.-W. Gyak, D.-P. Kim, J. Flow Chem. 2017, 7, 72, DOI: 10.1556/1846.2017.00013; b) A. J. Capel, R. P. Rimington, M. P. Lewis, S D. R. Christie, Nat. Rev. Chem. 2018, 2, 422, DOI: 10.1038/s41570-0180058-y.

[107] P. J. Kitson, M. H. Rosnes, V. Sans, V. Dragone, L. Cronin, Lab Chip 2012 12, 3267, DOI: 10.1039/C2LC40761B.

[108] M. D. Symes, P. J. Kitson, J. Yan, C. J. Richmond, G. J. T. Cooper, R. W Bowman, T. Vilbrandt, L. Cronin, Nat. Chem. 2012, 4, 349, DOI: 10.1038/ nchem.1313.

[109] P. J. Kitson, M. D. Symes, V. Dragone, L. Cronin, Chem. Sci. 2013, 4, 3099, DOI: $10.1039 / C 3 S C 51253 C$

[110] H. Gong, B. P. Bickham, A. T. Woolley, G. P. Nordin, Lab Chip 2017, 17, 2899, DOI: 10.1039/C7LC00644F.

[111] F. Kotz, P. Risch, D. Helmer, B. E. Rapp, Adv. Mater. 2019, 1805982, DOI: 10.1002/adma.201805982.

[112] J. M. Neumaier, A. Madani, T. Klein, T. Ziegler, Beilstein J. Org. Chem. 2019, 15,558 , DOI: 10.3762 /bjoc. 15.50 .

[113] Z. X. Rao, B. Patel, A. Monaco, Z. J. Cao, M. Barniol-Xicota, E. Pichon, M. Ladlow, S. T. Hilton, Eur. J. Org. Chem. 2017, 6499, DOI: 10.1002/ ejoc. 201701111

[114] B. Gutmann, M. Köckinger, G. Glotz, T. Ciaglia, E. Slama, M. Zadravec, S. Pfanner, M. C. Maier, H. Gruber-Wölfler, C. Oliver Kappe, React. Chem. Eng. 2017, 2, 919, DOI: 10.1039/C7RE00176B.

[115] S. V. Ley, D. L. Browne, M. O'Brien, in 'Flow Chemistry in Organic Synthesis', 2018 ed., Eds. T. F. Jamison, G. Koch, Georg Thieme Verlag, Stuttgart, 2018, p., DOI: 10.1055/sos-SD-228-00177.
[116] D. E. Fitzpatrick, S. V. Ley, React. Chem. Eng. 2016, 1, 629, DOI: 10.1039/ C6RE00160B

[117] a) R. Baxendale Ian, L. Brocken, J. Mallia Carl, in 'Green Processing and Synthesis', Vol. 2, 2013, p. 211, DOI: 10.1515/gps-2013-0029; b) I. R. Baxendale, J. Chem. Technol. Biotechnol. 2013, 88, 519, DOI: 10.1002/ jctb.4012.

[118] M. O. Kitching, O. E. Dixon, M. Baumann, I. R. Baxendale, Eur. J. Org. Chem. 2017, 2017, 6540, DOI: 10.1002/ejoc.201700904; b) E. Godineau, C. Battilocchio, M. Lehmann, S. V. Ley, R. Labes, L. Birnoschi, S. Subramanian, C. S. Prasanna, A. Gorde, M. Kalbagh, V. Khade, A. Scherrer, A. C. O'Sullivan, Org. Process Res. Dev. 2018, 22, 955-962, DOI: 10.1021/ acs.oprd.8b00095.

[119] J. C. Pastre, D. L. Browne, S. V. Ley, Chem. Soc. Rev. 2013, 42, 8849, DOI: $10.1039 / \mathrm{C} 3 \mathrm{CS} 60246 \mathrm{~J}$.

[120] R. E. Ziegler, B. K. Desai, J.-A. Jee, B. F. Gupton, T. D. Roper, T. F. Jamison, Angew. Chem. Int. Ed. 2018, 57, 7181, DOI: 10.1002/anie.201802256.

[121] M. D. Hopkin, I. R. Baxendale, S. V. Ley, Chem. Comm. 2010, 46, 2450, DOI: $10.1039 /$ C001550D.

[122] B. J. Deadman, C. Battilocchio, E. Sliwinski, S. V. Ley, Green Chem. 2013, 15, 2050, DOI: 10.1039/C3GC40967H.

[123] S. Newton, C. F. Carter, C. M. Pearson, L. de C. Alves, H. Lange, P. Thansandote, S. V. Ley, Angew. Chem. Int. Ed. 2014, 53, 4915, DOI: 10.1002/anie.201402056

[124] a) J. Sedelmeier, S. V. Ley, I. R. Baxendale, M. Baumann, Org. Lett. 2010, 12, 3618, DOI: 10.1021/ol101345z; b) T. Noël, J. R. Naber, R. L. Hartman, J. P. McMullen, K. F. Jensen, S. L. Buchwald, Chem. Sci. 2011, 2, 287, DOI: 10.1039/COSC00524J; c) G. Giri, L. Yang, Y. Mo, K. F. Jensen, Cryst. Growth Des. 2019, 19, 98, DOI: 10.1021/acs.cgd.8b00999.

[125] C. Battilocchio, B. J. Deadman, N. Nikbin, M. O. Kitching, I. R. Baxendale, S. V. Ley, Chem. Eur. J. 2013, 19, 7917, DOI: 10.1002/chem.201300696.

[126] a) P. Sá Gomes, A. E. Rodrigues, Chem. Eng. Technol. 2012, 35, 17, DOI: 10.1002/ceat.201100281; b) A. G. O’Brien, Z. Horváth, F. Lévesque, J. W. Lee, A. Seidel-Morgenstern, P. H. Seeberger, Angew. Chem. Int. Ed. 2012, 51, 7028, DOI: 10.1002/anie.201202795.

[127] D. E. Fitzpatrick, R. J. Mutton, S. V. Ley, React. Chem. Eng. 2018, 3, 799, DOI: 10.1039/C8RE00107C.

[128] M. Colella, C. Carlucci, R. Luisi, Top. Curr. Chem. 2018, 376, 46, DOI: 10.1007/s41061-018-0225-0.

[129] a) I. R. Baxendale, S. C. Schou, J. Sedelmeier, S. V. Ley, Chem. Eur. J. 2010, 16, 89, DOI: 10.1002/chem.200902906; b) I. R. Baxendale, S. V. Ley, A. C. Mansfield, C. D. Smith, Angew. Chem. Int. Ed. 2009, 48, 4017, DOI: 10.1002/anie.200900970; c) I. R. Baxendale, S. V. Ley, Bioorg. Med. Chem. Lett. 2000, 10, 1983, DOI: 10.1016/S0960-894X(00)00383-8.

[130] M. Baumann, I. R. Baxendale, L. J. Martin, S. V. Ley, Tetrahedron 2009, 65, 6611, DOI: 10.1016/j.tet.2009.05.083.

[131] Z. Qian, I. R. Baxendale, S. V. Ley, Chem. Eur. J. 2010, 16, 12342, DOI: 10.1002/chem.201002147.

[132] R. I. Storer, T. Takemoto, P. S. Jackson, S. V. Ley, Angew. Chem. Int. Ed. 2003, 42, 2521, DOI: 10.1002/anie.200351413.

[133] Chembeads: Improving Artificial Intelligence Through Human Ingenuity, https://stories.abbvie.com/stories/chembeads-improving-artificial-intelligence-through-human-ingenuity.htm.

[134] a) C. H. Hornung, M. R. Mackley, I. R. Baxendale, S. V. Ley, Org. Process Res. Dev. 2007, 11, 399, DOI: 10.1021/op700015f; b) L. J. Martin, A. L. Marzinzik, S. V. Ley, I. R. Baxendale, Org. Lett. 2011, 13, 320, DOI: 10.1021/ol1027927.

[135] A. Adamo, P. L. Heider, N. Weeranoppanant, K. F. Jensen, Ind. Eng. Chem. Res. 2013, 52, 10802, DOI: 10.1021/ie401180t.

[136] D. X. Hu, M. O’Brien, S. V. Ley, Org. Lett. 2012, 14, 4246, DOI: 10.1021/ ol301930h.

[137] R. M. Myers, K. A. Roper, I. R. Baxendale, S. V. Ley, in 'Modern Tools for the Synthesis of Complex Bioactive Molecules', 2012, p., DOI: 10.1002/9781118342886.ch11.

[138] a) T. Noël, V. Hessel, ChemSusChem 2013, 6, 405, DOI: 10.1002/ cssc.201200913; b) A. M. Polyakov, L. E. Starannikova, Y. P. Yampolskii, J. Membrane Sci. 2003, 216, 241, DOI: 10.1016/S0376-7388(03)00077-2.

[139] G. Wu, A. Constantinou, E. Cao, S. Kuhn, M. Morad, M. Sankar, D. Bethell, G. J. Hutchings, A. Gavriilidis, Ind. Eng. Chem. Res. 2015, 54, 4183, DOI: 10.1021/ie5041176. 